\title{
NON-DESTRUCTIVE MODULUS TESTING AND PERFORMANCE EVALUATION FOR ASPHALT PAVEMENT REFLECTIVE CRACKING MITIGATION TREATMENTS
}

\author{
Can $\mathrm{CHEN}^{1}$, Shibin $\mathrm{LIN}^{2}$, Ronald Christopher WILLIAMS 3 , Jeramy Curtis ASHLOCK ${ }^{4}$ \\ ${ }^{1}$ Chemco Systems, Bay Road 2800, Redwood City 94063, USA \\ ${ }^{2}$ Research Associate, Center for Advanced Infrastructure and Transportation, \\ Rutgers University, Brett Rd 100, Piscataway 08854, USA \\ ${ }^{3,4}$ Dept of Civil, Construction and Environmental Engineering, \\ Iowa State University, 813 Bissell Road, Ames 50011, USA
}

Received 16 June 2017; accepted 10 October 2017

\begin{abstract}
Reflective cracking is a common type of pavement distress, which manifests as cracks in an underlying layer propagating through to the surface of a pavement structure. To minimize reflective cracking of asphalt layers in composite pavements, four treatments are commonly used: standard/full rubblization, modified rubblization, crack and seat, and rock interlayer. The four types of treatment were evaluated to determine their effectiveness in mitigating reflective cracking via non-destructive Falling Weight Deflectometer tests and Surface Wave Method tests to measure layer modulus, along with field pavement performance surveys. It is found that moduli measurements from Surface Wave Method tests have reduced uncertainty comparing to those from Falling Weight Deflectometer tests, (2) the moduli of thin rock interlayers were captured by Surface Wave Method, but missed by Falling Weight Deflectometer. In addition, the Surface Wave Method results show that (1) crack and seat treatments provide the highest moduli, followed by modified rubblization, and (2) standard rubblization and rock interlayers provide moduli that are slightly lower than the other two treatments. Pavement performance survey was also conducted concurrently with the in-situ modulus tests. Based on the results of this study, modified rubblization and rock interlayer treatments are recommended for mitigation of reflective cracking.
\end{abstract}

Keywords: concrete rubblization, Falling Weight Deflectometer, reflective cracking, surface wave method.

\section{Introduction}

Composite pavements comprise a large portion of the paved highway surfaces in the State of Iowa and throughout the United States, mostly as the result of rehabilitation of Portland Cement Concrete (PCC) pavements. The traditional pavement design approach in Iowa has been employed to construct thick full-depth PCC pavements. When these pavements begin to show surface distress years later, they are usually overlaid with $50.8 \mathrm{~mm}$ to $152.4 \mathrm{~mm}$ (2 inches to 6 inches) of hot-mix of asphalt (HMA). Compared to full-depth pavement reclamation, composite pavement is a more cost-effective alternative owing to its better structural and functional performances. However, composite pavements often suffer from reflective cracking premature failure due to the horizontal and vertical displacements and strains in the underlying PCC layer. When HMA overlays are placed over jointed or cracked PCC pavements, cracking rapidly grows through the HMA overlay caused by concentrated horizontal movements from the expansion and contraction of the PCC slabs at joints and cracks, and from increased vertical deflection at the joints and cracks. The horizontal movements are usually caused by temperature changes in the PCC slab and HMA layers that exhibit transverse cracks during the freeze-thaw cycles. The thermal expansion and contraction differences for concrete and asphalt lead to the horizontal tensile stresses and strains from joint movements initiated at the bottom of the HMA overlay. The gradual reduction in load transfer at the joints and cracks in the PCC pavement, and heavy wheel loads that depress abutting slabs or crack faces are the main causes of vertical deflections (Al-Qadi, Buttlar, \& Baek, 2009; Von Quintus, Mallela, \& Lytton, 2010). Although reflec-

${ }^{*}$ Corresponding author. E-mail: shibin.lin.ctr@dot.gov

This is an Open Access article distributed under the terms of the Creative Commons Attribution License (http://creativecommons.org/licenses/by/4.0/), which permits unrestricted use, distribution, and reproduction in any medium, provided the original author and source are credited. 
tive cracking generally causes a minimal reduction of the structural capacity of a pavement, subsequent ingress of moisture and the effects of the natural environment and traffic result in premature distresses and early failure of the pavement. To minimize reflective cracking, four treatment methods have been widely used including standard/full rubblization, modified rubblization, crack and seat, and rock interlayer.

Rubblization and crack-and-seat treatments covert an existing rigid PCC layer into a "flexible" interlayer by breaking large PCC slabs into smaller pieces. These treatments reduce the effective slab length and therefore minimize horizontal movements and stress concentration caused by thermal expansion and contraction. It is found that rubblization significantly retards reflective cracking development in composite pavements in Iowa and Illinois (Chen et al., 2015; Heckel, 2002). The sizes of broken pieces with standard rubblization treatments are normally much smaller than the sizes of crack-and-seat treatments. However, a smaller broken size does not always guarantee that a PCC interlayer will have better performance, especially when encountering poor subgrade soil conditions, a lack of an aggregate base, and the use of thin PCC layers (Jansen, 2006). To overcome these challenges, modified rubblization is employed to produce larger broken pieces that provide a higher modulus for structural support. The multi-head breaker (MHB) has most often been used in Iowa to perform standard rubblization and modified rubblization. The MHB is a self-propelled unit with multiple drop hammers mounted at the rear of the machine. The hammers are set in two rows and strike the pavement approximately every $114.0 \mathrm{~mm}$ (4.5 inches). The hammers have variable drop heights and variable cycling speeds to break the concrete layer in variable sizes (Antigo, 2017). The particle size specifications and visual descriptions for each treatment type are summarized as follows. Standard rubblization is typical $50.8 \mathrm{~mm}$ (2 inches) particles at the surface, $152.4 \mathrm{~mm}$ to $304.8 \mathrm{~mm}$ (from 6 inches to 12 inches) particles at the bottom of PCC slabs. Modified rubblization has a maximum size of $304.8 \mathrm{~mm}$ (12 inches) at the surface, significant surface spalling, and a surface appearance ranging from smooth to pulverized. Crack and seat typically has $457.2 \mathrm{~mm}$ to $914.4 \mathrm{~mm}$ (18 inches to 36 inches) spaced cracks at the surface, little to no surface spalling, and spider-web appearance. Rock interlayer has an added "flexible" rock layer in between the HMA overlay and untreated PCC slabs to eliminate joints and cracks that reflect through a bituminous concrete overlay from untreated PCC layer. The rock interlayer usually has a thickness of $25.4 \mathrm{~mm}$ to $76.2 \mathrm{~mm}$ ( 1 inches to 3 inches) with $9.5 \mathrm{~mm}$ to $19.1 \mathrm{~mm}$ ( $1 / 2$ to $3 / 4$ inch) Type A rock placed wet through a paver and then static rolled (APAI, 2012). The roadway rocks have a good interlock and abrasion-resistance characteristic so that the interlayer would remain in position, while the asphalt layer is placed and compacted. The rock interlayer is strong and durable under construction traffic, and thus is directly placed over a deteriorated PCC layer as a stress-relief layer to reduce reflective cracking or serves as a levelling course for a PCC layer that already has been subjected to a crack-and-seat treatment.

\section{Falling Weight Deflectometer and Surface Wave Method for modulus estimation}

The modulus of the rubblized layer and rock interlayer cannot be evaluated directly because these layers are beneath the asphalt overlay. In addition, intact samples cannot be obtained for rubblized PCC pavement and rock interlayer, in most cases, retrieved are unrepresentative samples and samples are lack of cohesiveness to hold themselves as a core. The most practical approach for the modulus estimation of the underlying treated layer is through non-destructive testing using the Falling Weight Deflectometer (FWD) and geophysical Surface Wave Method (SWM). In this study, FWD and SWM tests were employed to measure the modulus of pavement structures after reflective cracking mitigation treatments. The FWD test applies a transient load pulse on a pavement surface to simulate the magnitude and duration of a single rolling wheel load. The resulting pavement deflections at selected radial locations from the loading centre are measured by a series of sensors (e.g., geophones), from which deflection is obtained. The stiffness profile of the tested pavement site is back calculated by matching the FWD experimental surface deflection to theoretical counterparts calculated for assumed stiffness profiles (FHWA, 2000). The FWD deflection data in this study was collected using a JILS-20 FWD by applying a step loading sequence of $40 \mathrm{kN}$. The geophone offsets were 203,305, 457, 610,914, 1219 and $1524 \mathrm{~mm}(8,12,18,24,36,48$ and 60 inches) away from the loading centre.

In SWM testing, a small transient impact is applied on a pavement surface to generate surface waves having a range of wavelengths to cover the depths of interest. The experimental dispersion characteristics of the generated surface waves in the layered pavement structure, typically expressed in the form of dispersion curves, contain the stiffness profile information. The stiffness profile of the tested pavement site is back calculated by matching the experimental dispersion curve to theoretical counterparts calculated by forward modelling for assumed stiffness profiles (Lin \& Ashlock, 2011, 2015; Lin, Ashlock, \& Williams, 2016; Lin et al., 2015; Nazarian, 1984; Park, Miller, \& Xia, 1998; Ryden, Ulriksen, Park, \& Miller, 2002). Surface wave tests in this study were carried out using the multichannel simulation with one receiver (MSOR) test method proposed by Ryden et al. (2002) and the MSOR testing system developed by Lin and Ashlock $(2011,2015)$. A $0.34 \mathrm{~kg}$ ball-peen hammer with an accelerometer attached as a trigger was used as the moving impact source, and a second accelerometer was fixed at zero offsets on the asphalt surface. Each test had twenty-four successive impacts, with both the first impact offset and the impact spacing equal to $5 \mathrm{~cm}$ (Figure 1). The experimental dispersion characteristics of the MSOR data were extracted 
a) surface wave equipment in field

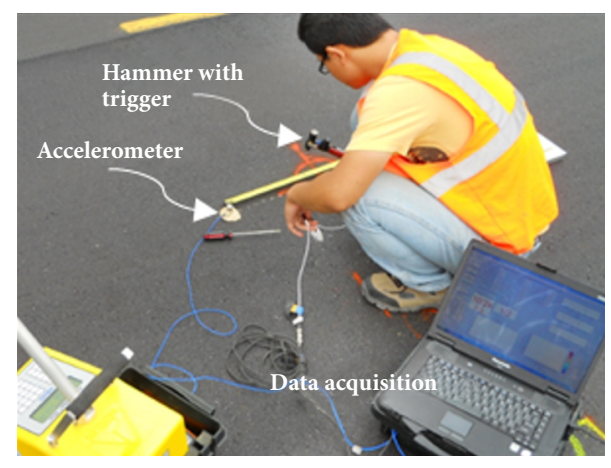

b) schematic of surface wave testing system

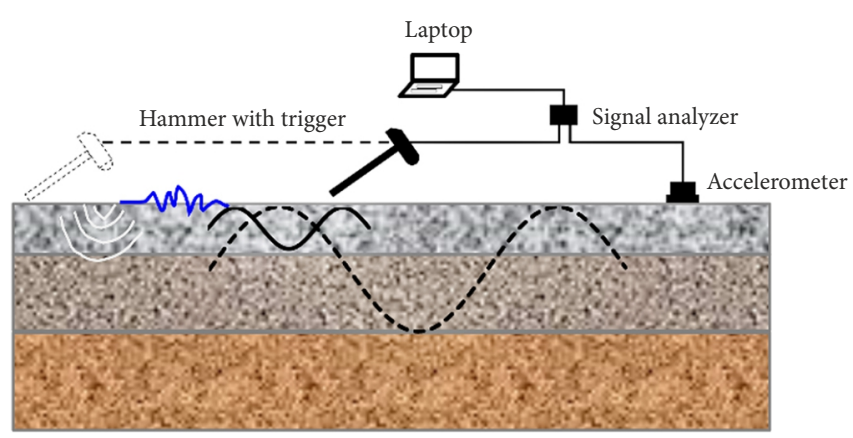

Figure 1. Surface wave method

using the phase-velocity and intercept-time scanning scheme proposed by Lin and Ashlock (2015). The frequency range of the dispersion characteristics is from $100 \mathrm{~Hz}$ to $5000 \mathrm{~Hz}$, the wavelengths of which cover the depths of interest for the pavements and base layers in the present study. Finally, the genetic-simulated annealing (GSA) algorithm developed by Lin (2014) was employed to back-calculate shear wave velocities, which were used to calculate Young's moduli for assumed densities and Poisson's ratios. Moduli obtained from SWM tests are in the very small strain regime, in contrast to those measured under larger strains and deflections in FWD tests. The effect of strain amplitude on modulus for both testing methods is discussed in the following section.

\section{Field tests, surveys, and analysis}

Sixteen freeway sections in Iowa were selected in this study, all road sections belong to the county road system with relatively low traffic volume. These include one conven- tional composite section without any treatment, two with standard rubblization, and eight with modified rubblization, two with crack and seat, and three with rock interlayers. Modified rubblization accounts for a large portion of interlayer treatments in Iowa due to the prevalence of soft subgrades consisting of silty and clayey soils. Table $1 \mathrm{de}-$ tails the sixteen sections, including location (route number and county), treatment type, and pavement structural information. The route numbers for the sixteen sections are used as the section names for simplicity in this study. At each pavement section, SWM tests were carried out at three to five locations. Non-destructive modulus tests and pavement distress survey was performed in the year 2014.

To examine the feasibility and accuracy of measuring the layer moduli by FWD and SWM tests, preliminary tests were first carried out using both methods on the first four pavement sections; D43, P29 (North), P29 (South), and P59 (Table 1). Temperature effects or adjustment was excluded because SWM tests were conducted at the same locations and time next to the FWD tests, and

Table 1. Details for sixteen pavement sections tested $(1 "=25.4 \mathrm{~mm})$

\begin{tabular}{|c|c|c|c|}
\hline No & Location & Treatment & Structures \\
\hline 1. & D43, Webster Co. & No treatment & 6" HMA + 8” PCC \\
\hline 2. & P29 (north) Webster Co. & Modified rubblization & 6" HMA + 1.5" Rock + 6" PCC \\
\hline 3. & P29 (south) Webster Co. & Modified rubblization & 6" HMA + 1.5" Rock + 6" PCC \\
\hline 4. & P59, Webster Co. & Modified rubblization & 4" HMA + 1.5" Rock + 6" PCC \\
\hline 5. & L55, Mills Co. & Standard rubblization & 7.5” HMA + 6” PCC \\
\hline 6. & D16, Black Hawk Co. & Standard rubblization & 5" HMA + 7" PCC \\
\hline 7. & D14, Webster Co. & Modified rubblization & 4" HMA + 1" Rock + 6" PCC \\
\hline 8. & G61 (east), Adair Co. & Modified rubblization & 4" HMA + 6" PCC \\
\hline 9. & G61 (west), Adair Co. & Modified rubblization & 4" HMA + 6" PCC \\
\hline 10. & N72, Adair Co. & Modified rubblization & 4" HMA + 6" PCC \\
\hline 11. & H24, Union Co. & Modified rubblization & 6" HMA + 7" PCC \\
\hline 12. & J 40 (west), Davis Co. & Crack and seat & 5" HMA + 6" PCC \\
\hline 13. & Y48, Scott Co. & Crack and seat & 6" HMA + 8” PCC \\
\hline 14. & Y4E, Scott Co. & Rock interlayer & 5" HMA + 1.5" Rock + 6" PCC \\
\hline 15. & H14, Montgometry Co. & Rock interlayer & 4" HMA + 1.5" Rock + 6" PCC \\
\hline 16. & J 40 (east), Davis Co. & Rock interlayer & 5" HMA + 2" Rock + 6" PCC \\
\hline
\end{tabular}

Note: "Rock" refers to rock interlayer. 
all tests were completed in same day. The FWD deflections and SWM dispersion trends for several tests at each of the first four sites are shown in Figure 2. Comparison of FWD deflections and SWM dispersion trends indicate that there is a strong correlation - the section with larger deflections has smaller phase velocities (Figure 2). The back-calculated pavement moduli for the two methods also show a strong correlation - the section with larger FWD deflections and smaller SWM phase velocities has smaller moduli (Figure 3).

Stiffness profiles for the first four sites were back calculated for the experimental data, resulting in the moduli values shown in Figure 3. The SWM moduli range from

a) deflections from FWD

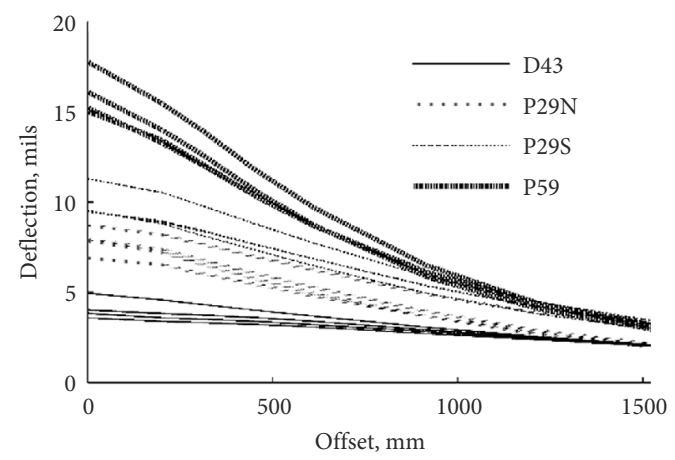

27.6 GPa to $41.4 \mathrm{GPa}$ for the concrete layer from the conventional composite section without any treatment, and from $10.3 \mathrm{GPa}$ to $20.7 \mathrm{GPa}$ for the rubblized concrete layers from the three modified rubblization sections. The SWM and FWD moduli are close to the conventional composite section without any treatment (Figure 3a). This indicates that the effect of strain amplitude on modulus is small when the PCC layer is intact. Results of FWD subgrade moduli are almost imperceptible in the figure since the average subgrade modulus is only around $0.11 \mathrm{GPa}$.

The effect of strain amplitude on modulus is evident for the modified rubblization sections. The SWM moduli of the modified rubblization PCC layers are typically higher

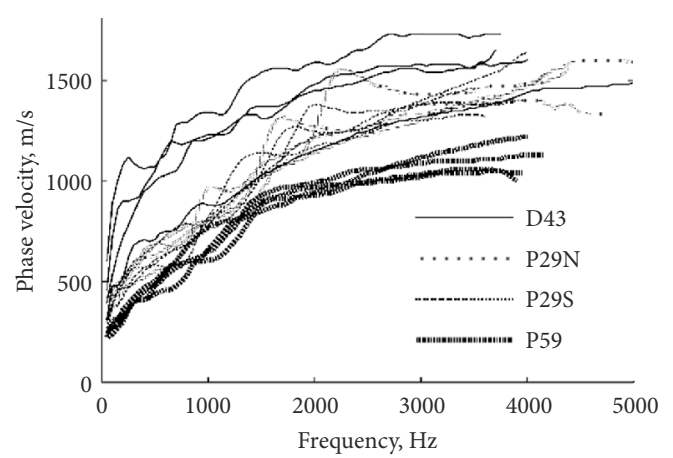

Figure 2. Experimental data for the first four sites

a) D43 section (no treatment)

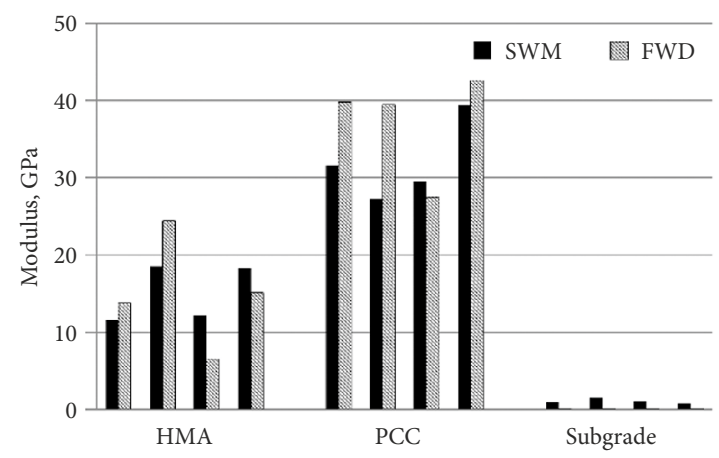

c) P29-south bound (modified rubblization)

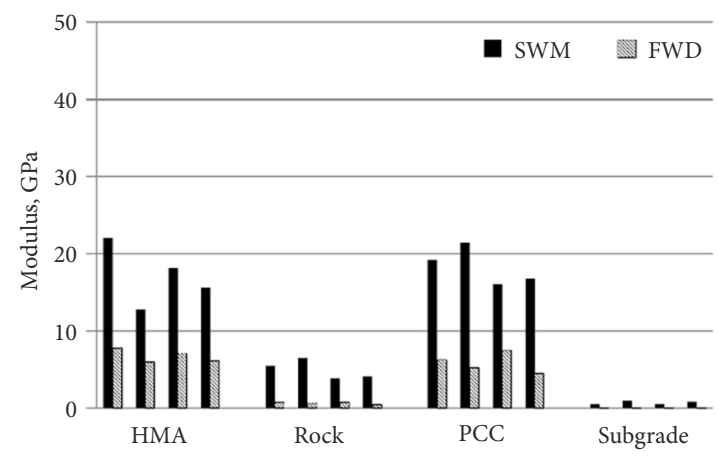

b) P59 section (modified rubblization)

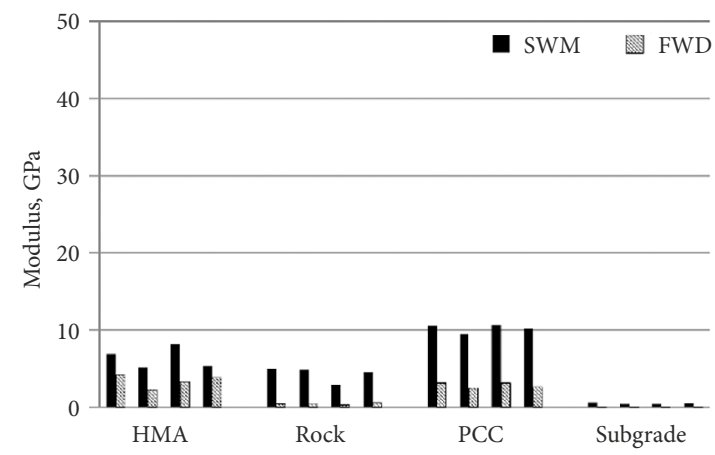

d) P29-north bound (modified rubblization)

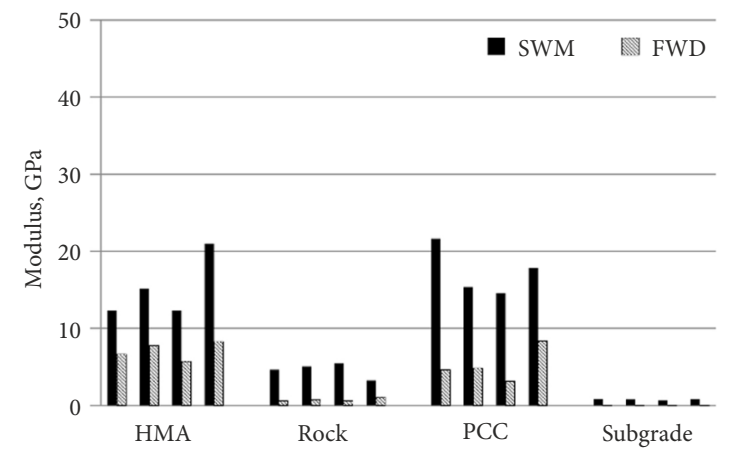

Figure 3. Comparison of FWD and SWM results 
than the FWD values by a factor of three as shown in Figures $3 b-d$. The difference is due to the fact that the FWD test has larger strains than the SWM test. As the strain increases, the modulus generally decreases (Bardet, Ichii, \& Lin, 2000; Li, Ashlock, Lin, \& Vennapusa, 2017; Ryden \& Mooney, 2009). The differences among the subgrade moduli are more significant. The SWM subgrade moduli range from $0.45 \mathrm{GPa}$ to $1.38 \mathrm{GPa}$, while the FWD values are from $0.045 \mathrm{GPa}$ to $0.138 \mathrm{GPa}$. The average FWD subgrade moduli for the modified rubblization sections is around $0.055 \mathrm{GPa}$, which is lower than that of the conventional composite section without any treatment $(0.11 \mathrm{GPa}$ for D43). According to the minimum strength requirement $0.069 \mathrm{GPa}$ for the foundation layers of rubblization pavement specified by the Wisconsin Department of Transportation (DOT), the results seem to indicate that the foundation layer of rubblized sections in Iowa cannot provide sufficient structural support (Wisconsin DOT, 2007).

Moreover, it is noticed that a wide range of moduli from $0.069 \mathrm{GPa}$ to $2.8 \mathrm{GPa}$ for the rock interlayers were obtained using FWD back-calculation, mainly because rock interlayer is only about $25-50 \mathrm{~mm}$ thick (1-2 inches). This considerable uncertainty leads to inaccuracy in predicting a pavement response, requiring an engineer to choose an appropriate initial back-calculation value and select a final value based upon experience. For this study, the initial back-calculation value for the rock-interlayer was chosen to be $0.62 \mathrm{GPa}$ as reported by Chen, Zhang, and Lambert (2013), and the final back-calculated moduli were constrained between $0.27 \mathrm{GPa}$ and $1.1 \mathrm{GPa}$, giving a coefficient of variation - COV of $37 \%$. In contrast to the considerable uncertainty of the FWD back-calculated values for the rock interlayer, SWM moduli for this layer range from $3.0 \mathrm{GPa}$ to $6.5 \mathrm{GPa}$ with a lower COV of $21 \%$.

The SWM and FWD moduli of the HMA surface layers from the two P29 sections are higher than that of the P59 section. This is likely because of the higher thickness and smaller strains of the HMA layers for the P29 sections (152.4 mm/6 inches) compared to the P59 section (101 mm/4 inches) thickness.
Various studies have reported that the surface wave dispersion trends are much smoother and more continuous for the flexible pavements than for the PCC and composite pavements due in part to the large contrast in moduli between the PCC layers and the underlying base or subgrade material. FWD was likely unable to predict reasonable modulus values for the base course layers beneath the concrete pavements and thin asphalt layer (Alexander, 1992; Gucunski, Sauber, Maher, \& Rascoe, 2009; Mallick, Bradley, \& Nazarian, 2006). In this study, the SWM has also shown a reduced uncertainty/variability for the thin rock interlayer properties, while the testing system is much more portable and economical compared to FWD. Thus, the moduli of the remaining 12 pavement sections were measured using only the SWM.

Figure 4 shows the average moduli values for the untreated and treated layers as measured by SWM for all sixteen-pavement sections. For all sixteen-pavement sections, testing was conducted in six weeks and temperature variation and effect is very limited, especially for the modulus of PCC and aggregate materials. The average moduli of rubblized PCC layers decrease as the size of the concrete fragments decreases. The moduli for the rock interlayers and standard rubblized layers are much lower than the modified rubblization and crack and seat treatments. During the standard rubblization process, the PCC slabs were broken into small, interconnected pieces that serve as an aggregate base course. This treatment layer behaves more like a high-strength/high-modulus granular base, with stiffness close to that of a rock-interlayer of dense-graded choke-stone. The rock interlayers consisted of Type A aggregates with a maximum Los Angeles abrasion loss of $40 \%$ and freeze-thaw loss of $15 \%$ (Iowa DOT, 2015). The Y48 project with the crack and seat treatment has very high moduli owing to the thicker concrete layer (203 $\mathrm{mm} / 8$ inches), as listed in Table 1 and the dense and stiff steel slag in the HMA layer.

The standard error for each project is presented as an error bar in Figure 4. Generally, the error increases as the layer stiffness increases. To evaluate whether the in-situ

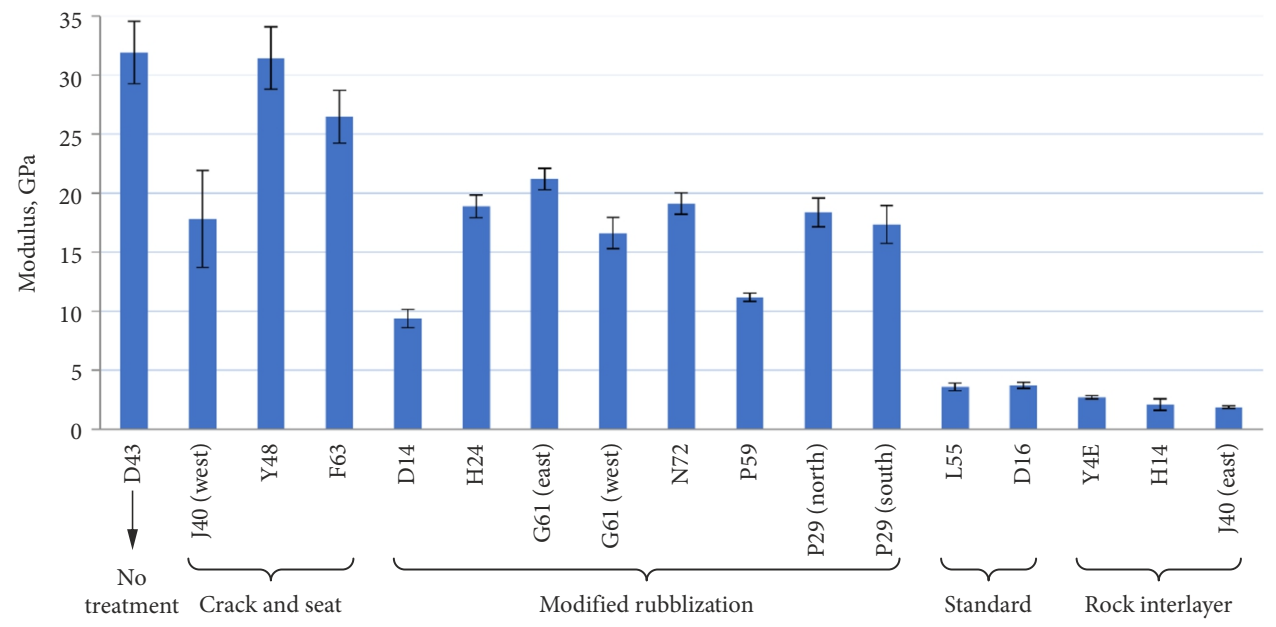

Figure 4. Mean modulus and standard error of the untreated/treated layers for each project 
moduli obtained with the two methods have statistical differences, Tukey's honest significant difference (HSD) test was used for multiple comparisons. This test provides meaningful comparisons when the sample sizes are unequal and provide more conservative results compared to other multi-comparison tests (Hayter, 1984). As shown in Table 2, the statistical test results demonstrate that:

1) the intact PCC layer has the highest moduli,

2) the crack and seat and modified rubblization layers have intermediate moduli, and

3) the rock interlayer and standard rubblization layers have the lowest moduli.

To determine, which treatment is most effective in minimizing reflective cracking, the surveys of pavement performance distress were conducted on a randomly selected 650-meter section for each project at the time of the field tests. Considering the typical plain-concrete pavement joint spacing, transverse cracks at regular and appropriately spaced intervals (approximately 5 to $6 \mathrm{~m}$ ) were considered reflective cracks. The survey for reflective cracking followed the method defined in the "Distress Identification Manual for the Long-Term Pavement Performance (LTPP) Project" (FHWA, 2003). Reflective cracking survey results are summarized in Table 3. In general, none of the pavement sites had rutting problems, implying that both the rubblized concrete and the rock interlayer system possess sufficient shear strength for rutting resistance for low traffic-volume county roads. A lack of comparable control pavement sections prevents a firm conclusion about the ability for these treatments in reflective cracking mitigation. However, it is clear that the treated pavement sections exhibited good performance, with no reflective cracks developing within the first three years of service. A simple reflective crack index (RCI) formula proposed by Chen et al. (2015) was employed to quantify the amount of reflective cracking Eq. (1):

$$
\mathrm{RCI}=\text { Low } \cdot 1+\text { Medium } \cdot 3+\text { High } \cdot 6,
$$

where Low, Medium and High describe the severity levels of cracking according to LTPP survey method.

A low severity level is defined as an unsealed crack with a mean width $\leq 6 \mathrm{~mm}$, any crack with a mean width $>6 \mathrm{~mm}$ and $\leq 19 \mathrm{~mm}$ is considered as medium level reflective cracking, and the high severity level cracking refers to the cracks larger than $19 \mathrm{~mm}$ in width. Considering the common concrete joint spacing $(4.5 \mathrm{~m}$ to $6.1 \mathrm{~m})$ and transverse cracking along the HMA overlay spaced in such distance was counted as reflective cracking. The index is calculated to account for the condition of reflective cracking based upon the extent of reflective cracking and a weighting function of the crack severity. A larger/wider reflective crack has a higher weighting factor. The results in Table 3 show that the D43 section without treatment has the most severe cracking with the highest RCI value. The L55 and D16 sections with standard rubblization having the longest service life developed only a moder-
Table 2. Layer moduli and ranking obtained by multiple comparison tests

\begin{tabular}{|l|c|c|c|c|}
\hline \multicolumn{1}{|c|}{ Method } & \multicolumn{2}{|c|}{ Ranking } & \multicolumn{2}{c|}{$\begin{array}{c}\text { Mean Young's } \\
\text { Modulus, GPa }\end{array}$} \\
\hline No treatment & A & & & 31.3 \\
\hline Crack and seat & & B & & 20.4 \\
\hline Modified rubblization & & B & & 16.2 \\
\hline Rubblization & & & C & 3.65 \\
\hline Rock interlayer & & & C & 2.22 \\
\hline
\end{tabular}

Table 3. Summary of pavement project reflective cracking condition

\begin{tabular}{|c|c|c|c|}
\hline $\begin{array}{l}\text { Section } \\
\text { name }\end{array}$ & $\begin{array}{l}\text { Service } \\
\text { year }\end{array}$ & $\begin{array}{l}\text { Reflective / Transverse } \\
\text { cracking condition }\end{array}$ & RCI \\
\hline $\mathrm{D} 43^{1}$ & 8 & $\begin{array}{l}6 \text { low, } 4 \text { medium and } 19 \text { high } \\
\text { severity cracks }\end{array}$ & 132 \\
\hline $\mathrm{J} 40$ (west) ${ }^{2}$ & 8 & $\begin{array}{l}7 \text { low, } 8 \text { medium and } 4 \text { high } \\
\text { severity cracks }\end{array}$ & 55 \\
\hline $\mathrm{Y}_{4} 8^{2}$ & 4 & No cracks & 0 \\
\hline P29 (north) ${ }^{3}$ & 2 & No cracks & 0 \\
\hline P29 (south) ${ }^{3}$ & 2 & No cracks & 0 \\
\hline D14 $4^{3}$ & 3 & No cracks & 0 \\
\hline P59 3 & 3 & No cracks & 0 \\
\hline $\mathrm{G} 61$ (east) $^{3}$ & 9 & $\begin{array}{l}15 \text { low, } 15 \text { medium, } \\
5 \text { high severity cracks }\end{array}$ & 90 \\
\hline G61 (west) $)^{3}$ & 9 & 3 low, 5 medium severity cracks & 18 \\
\hline $\mathrm{N} 72^{3}$ & 9 & $\begin{array}{l}2 \text { medium and } 4 \text { high severity } \\
\text { cracks }\end{array}$ & 14 \\
\hline $\mathrm{H} 24^{3}$ & 8 & $\begin{array}{l}2 \text { low, } 4 \text { medium and } 2 \text { high } \\
\text { severity cracks }\end{array}$ & 8 \\
\hline L55 $5^{4}$ & 13 & $\begin{array}{l}4 \text { low, } 15 \text { medium and } 3 \text { high } \\
\text { severity cracks }\end{array}$ & 67 \\
\hline D16 ${ }^{4}$ & 11 & $\begin{array}{l}3 \text { low, } 16 \text { medium } \\
\text { severity cracks }\end{array}$ & 51 \\
\hline $\mathrm{Y}_{4 \mathrm{E}^{5}}$ & 2 & No cracks & 0 \\
\hline $\mathrm{H} 14^{5}$ & 6 & $\begin{array}{l}1 \text { medium and } 4 \text { high } \\
\text { severity cracks }\end{array}$ & 13 \\
\hline $\mathrm{J} 40$ (east) $^{5}$ & 8 & $\begin{array}{l}6 \text { low, } 7 \text { medium and } \\
2 \text { high severity cracks }\end{array}$ & 39 \\
\hline
\end{tabular}

Note: the superscript number by the section name represents the treatment method: 1 - no treatment, 2 - crack and seat, 3 - modified rubblization, 4 - standard rubblization, 5 - rock interlayer.

ate amount of reflective cracking. Comparing the two J40 sections, the west part used the crack and seat method, whereas the east part used rock interlayer method due to the concern of potential premature failure and resulting repair costs. The results appear to indicate that the crack and seat treatment is less effective than the rock interlayer for reflective cracking control but the difference is small (RCI 55 vs. 39, Table 3). The rock interlayer and modified rubblization projects had nearly the same pavement performance with a small amount of cracking. 
Table 4. Comparison of layer moduli values

\begin{tabular}{|c|c|c|c|c|}
\hline Method & $\begin{array}{c}\text { No treatment, } \\
\text { PCC layer, GPa }\end{array}$ & $\begin{array}{c}\text { Crack and seat, } \\
\text { PCC layer, GPa }\end{array}$ & $\begin{array}{c}\text { Standard rubblized, } \\
\text { PCC layer, GPa }\end{array}$ & $\begin{array}{c}\text { Rock interlayer / } \\
\text { Granular base, GPa }\end{array}$ \\
\hline SWM in this study & $27.20-39.40$ & $7.71-36.70$ & $3.04-4.04$ & $1.59-2.96$ \\
\hline SWM from others & $\begin{array}{c}24.20-44.80 \\
\text { Alexander (1992) }\end{array}$ & N/A & $\begin{array}{c}0.55-2.76 \\
\text { Gucunski et al. (2009) }\end{array}$ & N/A \\
\hline FWD from others & $\begin{array}{c}47.80-65.00 \\
\text { Alexander (1992) }\end{array}$ & $\begin{array}{c}8.49-55.00 \\
\text { Korsgaard et al. (2005) }\end{array}$ & $\begin{array}{c}0.26-0.84 \\
\text { Ceylan, Gopalakrishnan, and Kim (2008) }\end{array}$ & $\begin{array}{c}0.30-0.69 \\
\text { Chen et al. (2013) }\end{array}$ \\
\hline
\end{tabular}

Finally, the measured SWM moduli in this research were compared to those from other studies, as presented in Table 4 . Being a more recently developed method, modified rubblization has no related literature on SWM tests and thus was excluded in this comparison. Alexander (1992) conducted both SWM and FWD tests on composite pavements, and he found that the PCC layer moduli obtained by SWM tests were slightly smaller than those from FWD tests were. The same trend was observed in this study, and the measured moduli are very close to the results from Alexander (1992). Using the FWD testing method to determine moduli for the crack and seat concrete method, Korsgaard, Pedersen, Rasmussen, and Königsfeldt (2005) found that the moduli change significantly before and after the asphalt overlay, and "between" or "on" the cracks. Their reported values vary considerably from $8.49 \mathrm{GPa}$ to $54.5 \mathrm{GPa}$. Gucunski et al. (2009) performed SWM tests directly on the surface of highly crushed standard rubblized concrete layer. Results show that the SWM moduli values from HMA overlay for standard rubblized sections from the present study are slightly higher with lower variability compared to the results of Gucunski et al. (2009).

\section{Conclusions}

The modulus and performance of four pavement reflective cracking mitigation treatments (i.e., standard rubblization, modified rubblization, crack and seat, and rock interlayer) were evaluated using non-destructive testing techniques. The conclusions are summarized as follows:

1. Surface Wave Method is an effective method for in-situ stiffness profiling of pavement systems. Surface Wave Method moduli of the Portland Cement Concrete layers agree well with the Falling Weight Deflectometer results for traditional untreated composite pavements.

2. The effect of strain amplitude on modulus is evident for the modified rubblization sections. The Surface Wave Method moduli are typically two to three times higher than the Falling Weight Deflectometer moduli.

3. Large uncertainty was obtained in the modulus measurements for thin rock interlayers and subgrade layers. The substantially lower Falling Weight Deflectometer modulus for the rock interlayers was caused by the following two reasons:
- the thin layers being generally undetectable by Falling Weight Deflectometer testing, and

- large strains imposed on the "flexible" choke stone layer.

4. For the four treatment methods, the crack and seat method has the highest Surface Wave Method moduli, followed by modified rubblization. The standard rubblization and rock interlayer methods gave slightly lower moduli values.

5. Results from the field surveys show that the traditional composite untreated pavement sections exhibit the greatest amount of reflective cracking, followed by the standard rubblization sections. Poor subgrade soil property is a reason to minimize the use of standard rubblization because the process of breaking a Portland Cement Concrete layer with large concrete slabs into a base layer with tightly interlocked small pieces has the potential to damage or destabilize the subgrade. The impaired subgrade soil is believed to be the cause for cases of the relatively poor performance of the standard rubblization method.

6. It is recommended to use the rock interlayer and modified rubblization methods in the field. However, additional projects should be monitored to support this recommendation.

\section{Acknowledgement}

The authors express their gratitude to the support for this work provided by Iowa Department of Transportation and Institute for Transportation at Iowa State University. Also thanks to Antigo Construction who provided useful consultation on concrete pavement rubblization for this research project.

\section{References}

Al-Qadi, I., Buttlar, W. G., \& Baek, J. (2009). Cost-effectiveness and performance of overlay systems in Illinois. Volume 2: Guidelines for Interlayer System Selection Decision When Used in HMA Overlays. Illinois Center for Transportation Series No. 09-045.

Asphalt Paving Association of Iowa - APAI. (2012). The Iowa asphalt report - the rise of the interlayer. Published by Asphalt Paving Association of Iowa, summer report, 2012, Ames, Iowa. 
Alexander, D. R. (1992). In-situ material characterization for pavement evaluation by the spectral analysis of surface waves method. Technical Report-GL-92-10. US Army Corps of Engineers.

Antigo. (2017). Rubblization. Retrieved from www.antigoconstruction.com/rubblization

Bardet, J. P., Ichii, K., \& Lin, C. H. (2000). User's manual for EERA. Department of Civil Engineering, University of Southern California.

Chen, X. W., Zhang, Z. J., \& Lambert, J. R. (2013). Field performance evaluation of stone interlayer pavement in Louisiana. Transportation Research Board Conference, CD-COM, Washington, D.C.

Chen, C., Williams, R. C., Marasinghe, M. G., Omunderson, J., Schram, S., \& Buss, A. (2015). Assessment of composite pavement performance by survival analysis. Journal of Transportation Engineering, 141(9). https://doi.org/10.1061/(ASCE)TE.1943-5436.0000784

Ceylan, H., Gopalakrishnan, K., \& Kim, S. (2008). Performance evaluation of rubblized pavements in Iowa. Final Report, IHRB Project TR-550. Institute for Transportation, Iowa State University, Ames, Iowa.

Federal Highway Administration - FHWA. (2000). LTPP manual for falling weight deflectometer measurements operational feld guidelines. FWHA-LTPP Technical Support Services Contractor, Beltsville, Maryland.

Federal Highway Administration - FHWA. (2003). Distress identification manual for the long-term pavement performance program. Publication No.: FHWA-RD-03-031. Virginia, USA.

Gucunski, N., Sauber, R., Maher, A., \& Rascoe, C. (2009). Modulus of rubblized portland cement concrete from surface wave testing. Transportation Research Record, (2014), 34-41. https://doi.org/10.3141/2104-04

Hayter, A. J. (1984). A proof of the conjecture that the TukeyKramer multiple comparisons procedure is conservative. The Annals of Statistics 12(1), 1-104.

https://doi.org/10.1214/aos/1176346392

Heckel, L. B. (2002). Rubblizing with bituminous concrete overlay - 10 years' experience in Illinois. Report No. IL-PRR-137. Illinois Department of Transportation, Springfield, Illinois.

Iowa Department of Transportation - Iowa DOT. (2010). Section 4120: Granular Surfacing and Granular Shoulder Aggregate. Retrieved from http://www.iowadot.gov/erl/current/GS/content $/ 4120$. htm

Jansen, J. (2006). Rubblization vs. crack and seat. Presentation at 2006 Great Iowa Asphalt Conference, 2006, Des Moines, Iowa.

Korsgaard, H. C., Pedersen, J. P., Rasmussen, M., \& Königsfeldt, S. (2005). Rehabilitation by cracking and seating of concrete pavement optimized by FWD analysis. International Conference on the Bearing Capacity of Road, Railway and Airfields, Norway.
Li, C., Ashlock, J. C., Lin, S., \& Vennapusa, P. (2017). In-situ multi-layered nonlinear modulus reduction characteristics of stabilized unpaved roads by surface wave and falling weight deflectometer method. Transportation Research Board 96th Annual Meeting. Washington, D.C, USA.

Lin, S. (2014). Advancements in active surface wave methods: modeling, testing, and inversion. $\mathrm{PhD}$ dissertation, Iowa State University.

Lin, S., \& Ashlock, J. C. (2011). A Study on issues relating to testing of soils and pavements by surface wave methods. Proceedings 38th Annual Review of Progress in Quantitative Nondestructive Evaluation. Burlington, USA.

Lin, S., \& Ashlock, J. C. (2015). Comparison of MASW and MSOR for surface wave testing of pavements. Journal of Environmental \& Engineering Geophysics, 20(4), 277-285. https://doi.org/10.2113/JEEG20.4.277

Lin, S., Ashlock, J. C., Kim, H., Nash, J., Lee, H. D., \& Williams, R. C. (2015). Assessment of nondestructive testing technologies for quality control/quality assurance of asphalt mixtures. Report, Iowa Department of Transportation, Iowa, USA.

Lin, S., Ashlock, J. C., \& Williams, R. C. (2016). Nondestructive quality assessment of asphalt pavements based on dynamic modulus. Construction and Building Materials, 112, 836-847. https://doi.org/10.1016/j.conbuildmat.2016.02.189

Mallick, R. B., Bradley, J. E. \& Nazarian, S. (2006). In-place determination of stiffness of subsurface reclaimed layers in thin surface hot-mix asphalt pavements. Transportation Research Record, (1949), 11-19. https://doi.org/10.3141/1949-02

Nazarian S. (1984). In situ determination of elastic moduli of soil deposits and pavement systems by spectral-analysis-of-surfacewaves method. PhD Thesis, 1984, The University of Texas at Austin. Retrieved from library.ctr.utexas.edu/digitized/TexasArchive/phase2/368-1F-CTR.pdf

Park, C. B., Miller, R. D., \& Xia, J. (1998). Imaging dispersion curves of surface waves on multichannel record: technical program with biographies. SEG, 68th Annual Meeting (pp. 1377-1380). New Orleans, USA.

Ryden, N., Ulriksen, P., Park, C. B., \& Miller, R. D. (2002). Portable Seismic Acquisition System (PSAS) for Pavement MASW. Proceedings of the Symposium on the Application of Geophysics to Engineering and Environmental Problems.

Ryden, N., \& Mooney, M. A. (2009). Analysis of surface waves from the light weight deflectometer. Soil Dynamics and Earthquake Engineering 29(7), 1134-1142. https://doi.org/10.1016/j.soildyn.2009.01.002

Von Quintus, L. H., Mallela, J., Lytton, L. R. (2010). Techniques for mitigation of reflective cracks. FAA Worldwide Airport Technology Transfer Conference, 2010, Atlantic City, USA.

Wisconsin Department of Transportation - Wisconsin DOT. (2007). Facilities Development Manual. Retrieved from https://trust.dot.state.wi.us/static/standards/fdm/14/TC14.pdf 